\title{
Estimation of Transportation Battery Second Life for use in Electricity Grid Systems
}

\author{
D. Strickland, L. Chittock, D Stone, M Foster, B Price
}

\begin{abstract}
This paper presents research from part of a larger project focusing on the potential development of commercial opportunities for the re-use of batteries on the electricity grid system, subsequent to their primary use in low and ultra-low carbon vehicles, and investigating the life cycle issues surrounding the batteries. The work has three main areas; Examination of fleet data in detail to investigate usage in $1^{\text {st }}$ life. Batteries that have passed through a battery recycler at the end of their first life have been tested within the laboratory to confirm the general assumption that remaining capacity of $\mathbf{8 0} \%$ after use in transportation is a reasonable assumption as a basis for $2^{\text {nd }}$ life applications. The second aspect of the paper is an investigation of the equivalent usage for three different second life applications based on connection to the electricity grid. Additionally the paper estimates the time to cell failure of the batteries within their second life application to estimate lifespan for use within commercial investigations.
\end{abstract}

Index Terms-Batteries, Electric Vehicles, Energy Storage, Frequency Response, Smart Grids.

\section{INTRODUCTION}

The use of battery systems within transportation, in the form of hybrid or electric vehicles is increasing. There is also significant interest in using electric vehicle batteries to help support the new smart grid functionality. Several credible sources, including the Department of Energy and Climate Change (DECC), Arup and Cenex [1] and Shepherd et al [2] reports, suggest there could be between 70,000 to 2.6 million electric and hybrid vehicles on the road by 2020. Typically, once an Electric Vehicle (EV) battery has degraded to nominally $70-80 \%$ of its original capacity it is considered to be at the end of its first life application. Assuming a typical battery capacity of around 5-24kWhr (Mild Hybrid Electric Vehicle (MHEV) 5kWh - Battery Electric Vehicle (BEV) 18 $24 \mathrm{kWh}$ battery), and a 10 year life span, this equates to a projection of batteries available for storage in second life applications of $>1$ GWhrs by 2025. Second life batteries should also be available at lower cost than new batteries, however reliability becomes an important issue as individual batteries may suffer from degraded performance or failure.

The remaining quality and life of a battery after its first life

This work was supported in part by the UK Technology Strategy Board (Ref 130708)

D Strickland, B. Price, L. Chittock are with the Department of Engineering and Applied Science, Aston University, Birmingham, B1 4ET, UK (e-mail: d.strickland@aston.ac.uk).

D. Stone and M Foster are with the Department of Electrical Engineering, Sheffield University, Sheffield, UK (e-mail: d.a.stone@sheffield.ac.uk). can be dependent on a number of factors including, but not limited to; the battery chemistry, the number of cycles, the discharge current, the State of Charge (SOC) or Depth of Discharge (DoD) swing, the charge throughput of a current micro-cycle and the cell temperature [3,4]. A variety of publications looking at some or all of these variables exist for a range of chemistries under a variety of laboratory and test based conditions. Typically the cell temperature is held to be constant (either ambient or a typical value of around $45^{\circ} \mathrm{C}$ ) $[5,6]$ and either a constant charge-discharge regime to a set DoD or a constant drive cycle is applied to the cells under test $[6,3]$. The results published aim to estimate the capacity fade or look at when cell failure occurs or estimate the remaining life[3,5]. This work is used to help investigate batteries from vehicles which have been driven as part of a large scale vehicle trial, where fixed cycles and fixed cell temperatures don't apply, to estimate the remaining life span for a second life application.

The incorporation of battery storage onto the utility grid presents three main revenue streams, available for second life batteries;

1. Peak load reduction on the distribution Network to allow for network re-enforcement costs to be deferred. (Customer base: Distribution Network Operator ( DNO))

2. Ancillary Service (or primary/secondary frequency response - Customer is ultimately National Grid through market mechanisms via DNO's or Energy service providers or Aggregators)

3. Provide customers with the means of optimising their energy demand patterns to suit market conditions. (large, small industry and domestic consumers through energy service providers)

Some previous work has been undertaken on the economics of second life batteries, most notably by Neubauer et Al[7] who look at cost comparisons between new and second life batteries based on a health factor related to estimated battery life and energy throughput (relating to a US peak load reduction application). Their work includes a number of fixed parameters such as a total battery life of 20 years, vehicle drive cycles from a more general study looking at all vehicle behavior and a fixed DoD of $60 \%$. The life span of the second life battery is then assumed as 20years minus first life.

This paper examines methods of estimating how much second life is available from second life batteries using an alternative method based primarily on usage data from EV and 
HEV trial data (as opposed to assumed data) looking at real DoD rates and then determining a remaining life span based on this, but not dependent on a fixed 20 year total life. The Energy throughput is not explicitly calculated but could be inferred to feed into other work if required. The data comes from the Technology Strategy Board (TSB) 'CABLED' (Coventry And Birmingham Low Emissions Demonstration) project, and the data on vehicle usage are used to estimate residual life in the batteries through a statistical based approach. The remaining life cycle can then be used within projects to estimate the business case for second life batteries under the three income streams described above.

Batteries that have passed through a battery recycler at the end of their first life have been tested within the laboratory to confirm the general assumption that remaining capacity of $80 \%$ after use in transportation is a reasonable assumption as a basis for 2 nd life applications. The third aspect of the paper is an investigation of the equivalent usage for three different second life applications based on connection to the electricity grid. The paper estimates the time to cell failure of the batteries within their second life application to estimate lifespan for use within commercial investigations. Different battery chemistries are not inherently seen as a problem, but the work here concentrates on a mixture of Nickel Metal Hydride (NiMH) and Lithium Ion batteries.

\section{BATTERY FIRST LIFE}

The 'CABLED' project was commissioned in 2009 by the Technology Strategy Board (TSB) with support from Advantage West Midlands (AWM). The aim of the trial was to showcase and demonstrate the use of ultra-low carbon vehicles (ULCV) in the West Midlands region. Usage data collected from each car was used to inform local authorities and vehicle manufacturers, providing them with a better understanding of ULCV technology; thus enabling the development of longer term policies. The data collected also provided an opportunity to investigate vehicle and battery usage, and the monitoring of any battery degradation issues that occurred over the period of the trial. Using this data on 'first life' usage, a picture of battery condition for second life application can be constructed.

\section{A. CABLED Vehicles}

The majority of the vehicles in the CABLED trial were pure electric vehicles (EVs). With a range of between 65-110 miles (depending on model), these vehicles are designed to meet the requirements of an urban household. Over 100 EVs were leased to members of the public or fleet operators for a minimum period of 12 months, with data collected over a 27 month period.

Each vehicle in the trial was fitted with a GPS and data logger, which recorded the usage, location and charging habits of each vehicle. Records were taken every minute whilst the car was in use, and every 15 minutes when not. The data collected allowed the following information to be attained:

- Frequency of individual journeys

- Length and duration of journeys

- Date \& time of journeys

- Energy used per journey
- Duration and amount of energy transferred during charge

- External ambient temperature

- Location of charging/parking, i.e. home, work, public etc.

- Average speed

\section{B. Vehicle usage}

The analysed data in table 1 , shows that the vehicles in the trial were driven for around 40 minutes per day on average. This was calculated by considering the total amount of time the vehicle was parked and subtracting from the total hours the car was operational. The RAC national traffic survey [7] and UK national travel survey [8] indicates that the figure of 40 minutes driving per day is not an unreasonable average for the population as a whole. This indicates that the vehicles used in the trial were undertaking representative driving cycles, and their usage is in keeping with the national average for other vehicle engine types.

TABLE I

Statistical driving usage/day

\begin{tabular}{|c|c|c|}
\hline \multicolumn{3}{|c}{ Statistical driving usage/day } \\
\hline Statistics & \% time parked & $\begin{array}{c}\text { Time in use } \\
\text { (daily) }\end{array}$ \\
\hline Mean & $97.32 \%$ & $00: 38$ \\
\hline Median & $97.30 \%$ & $00: 38$ \\
\hline St dev & $1.36 \%$ & $00: 19$ \\
\hline
\end{tabular}

The data relating to vehicle charging is shown in Fig. 1, 2 and 3 and summarised in Table II. Fig. 1 shows a distribution of the State of Charge when vehicles started charging. Between $20-80 \%$ the distribution is fairly evenly spread, indicating a variation in different user's behaviour and usage. Once plugged in, the majority of these vehicles are then fully charged as shown in Fig. 2. The State of Charge (SOC) increase is shown in Fig. 3. Whilst these results show variation in charging behaviour, typically people topped-up their battery before they began to run out of charge (i.e. $>20 \%$ remaining).

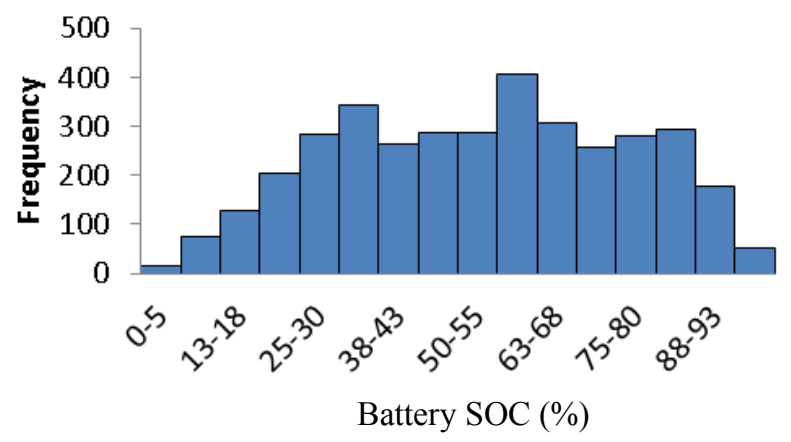

Fig. 1. Battery SOC before recharging

The profile for number of charges per day is shown in Fig. 4. On average the vehicles were charged 0.54 times per day (rougly equivalent to 1 charge every 2 days) with a standard deviation of 0.38 . A typical set of charging profiles are shown in Fig. 5.

Using the figures presented the following assumptions can be made:

1. The vehicles are operating on typical drive cycles.

2. Each vehicle is assumed to charge on a recurring cycle 
where the Depth of Discharge (DoD) is defined as:

$$
\mathrm{DoD}=\Delta \mathrm{SOC}
$$

The DoD is set $35 \%$ since this was the average increase per charge in the CABLED trial.

3 . The frequency of charging of all vehicles is 0.54 times per day - equivalent to approximately 200 times per year.

4. The vehicle life is 10 years (based on the 10 year, 100,000 miles power train warranties now on offer from some manufacturers).

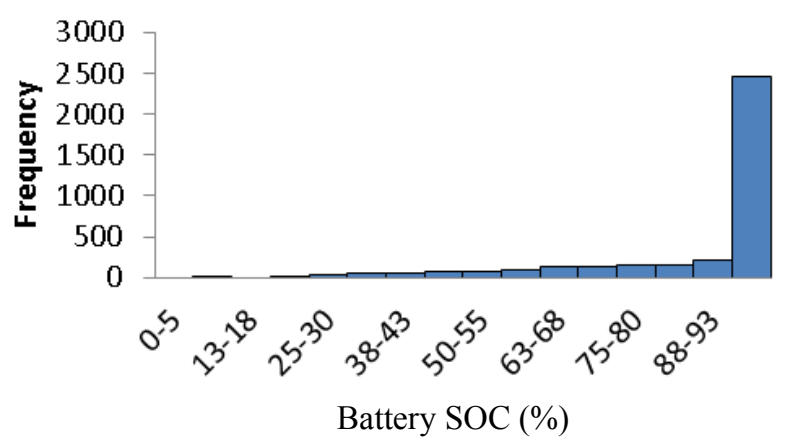

Fig. 2. Battery SOC after recharging

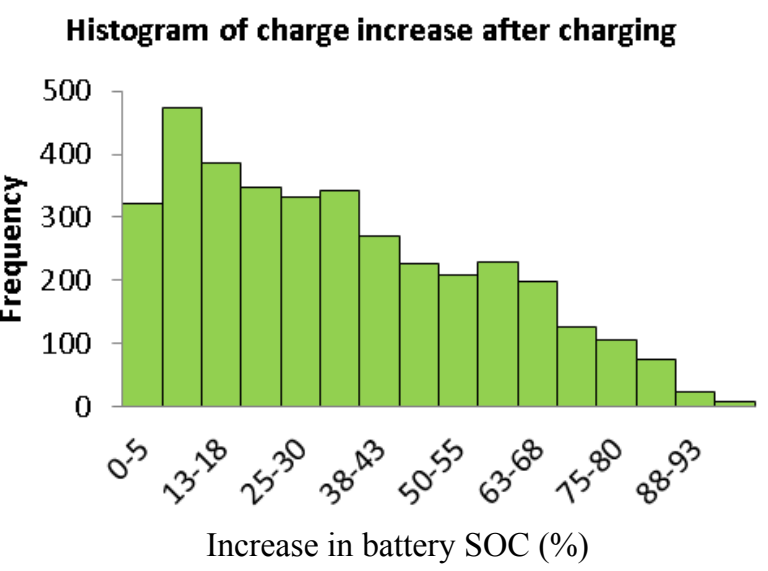

Fig. 3. Battery SOC change during charging

TABLE II

Mean battery charging (Not necessarily per day)

\begin{tabular}{|l|r|}
\hline \multicolumn{2}{|c|}{ Charging statistics } \\
\hline Mean SOC at start of charge (\%) & 54.07 \\
\hline Median SOC at start of charge (\%) & 55.00 \\
\hline Average charge time (hrs) & $02: 54: 40$ \\
\hline Median charge time (hrs) & $02: 34: 17$ \\
\hline Average SOC increase per charge (\%) & 34.32 \\
\hline
\end{tabular}

\section{Average number of charges per day per car}

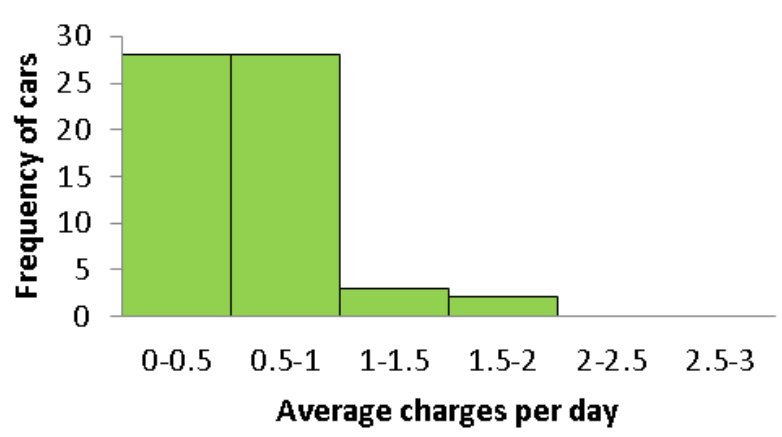

Fig. 4. Average number of charges per day per vehicle

\section{Typical charge profile for three vehicles over 100 days}

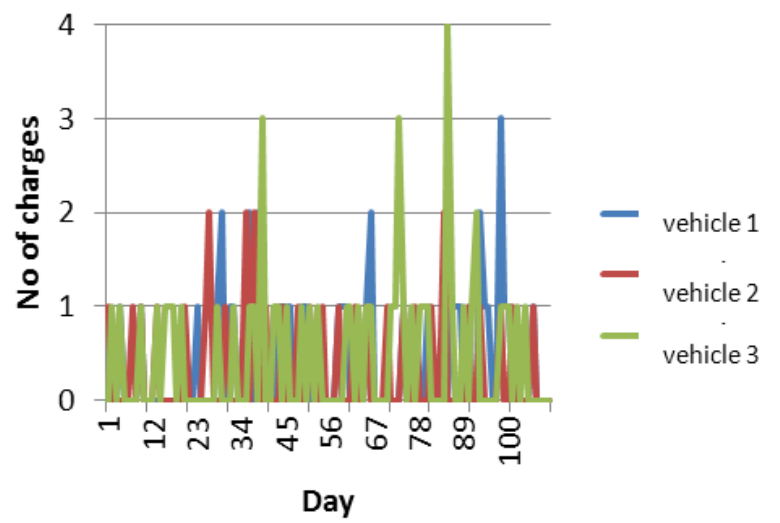

Fig. 5. Sample of the charging regime for three vehicles over 100 days

C. Theoretical battery degradation based on vehicle usage

Fig. 6 reproduced from [9] shows the 100\% DoD cycle equivalent (DoDCE) against depth of discharge until failure. Typically the manufacturer will plot the life span against the DoD as an exponential curve, but this is an alternative representation. (Note - a lower DoD has a greater number of cycles until failure as expected).

A nominal $100 \%$ DoD cycle equivalent is found by multiplying the number of cycles with the $\mathrm{DoD}$ as per equation (2):

DoDCE $=$ No cycles $x$ DoD

Since unequal amounts of energy flow out of batteries during discharge, the results were plotted in this way to enable comparison. The results in paper [9] were obtained from a relatively small data set using a single battery type and as such are only treated as indicative, allowing the methodology to estimate remaining life to be shown. This curve will be different for different battery chemistries and the results from this paper were used because the data was already published. Although this chemistry doesn't necessarily tie up with the battery types from vehicles on the CABLED trial the methodology is shown. 


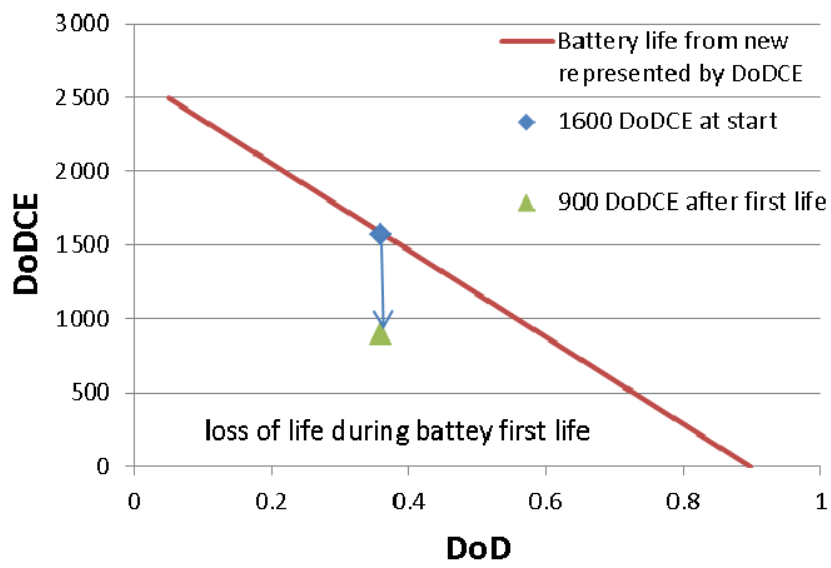

Fig. 6. Estimated battery life at 35\% DoD using data from [9], The blue diamond shows that for a DoD of $35 \%$ there is an estimated 1600 DoDCE of lifespan. After the first life the green triangle represents the 900 DoDCE that remains.

Using a nominal $35 \% \mathrm{DoD}$, the initial life span of the vehicle in DoDCE can be estimated at 1600 DoDCE cycles or approximately 4500 total cycles at this DoD. This is shown by the blue diamond in Fig. 6. If the lifespan of the vehicle is 10 years then the battery will go through 2000 charge/discharge cycles. The amount of life used up from equation 2 , is therefore equivalent to $0.35 \times 2000=700$ DoDCE. Subtracting the first life DoDCE usage away from the starting DoDCE yields a remaining life span of 900 DoDCE shown by the green triangle. This then acts as the starting point for the second life application for which a different DoD may be used.

However, not every driver discharges their vehicle by an average $35 \%$ DoD. Results from the CABLED project showed that some drivers top up twice a day and others less than 1 in every 3 days with the average being 200 times per year. If it is assumed that each vehicle is still driving 40 minutes per day (valid due to the low STD) then an additional two scenarios can be considered for someone topping up with low DoD $(10 \%)$ twice per day and someone topping up with high DoD $(70 \%) 100$ times per year. Within a year - the total SOC increase for the two vehicles is assumed to be the same (due to same time on road). Using equation 2, the remaining life span of the vehicle with $10 \%$ DoD is 1600 DoDCE after 10 years. The vehicle with $70 \%$ DoD will have an estimated zero remaining life span.

\section{Battery degradation experimental data}

This section looks at experimental data from both the CABLED project (looking for degradation trends within first two years of vehicle life) and data from testing batteries which have come through their first life and been passed on by a battery recycler for testing to look to try and confirm the validity of the theoretical data.

\section{1) Early life battery degradation using CABLED data}

Due to the data set available - the following methods were developed to best understand battery degradation in the CABLED vehicles:
Method 1: Analytical comparison of similar journeys (eg work to home) for the same vehicle at different times within the project time cycle. To try and minimize as many extraneous variables as possible, separate journeys were compared given similar ambient temperatures, initial state of charge, journey duration and journey distance. The total energy used for each journey was then compared to see if there were any degradation effects over time.

Method 2: A Monte-Carlo based approach, with data collected from many journeys (same battery and vehicle type but nonvehicle specific) over the project timespan. Average SOC usage per mile was plotted against ambient temperature and separated by date to see if the energy needed per mile varied over time. Instead of taking out the random effects caused by issues mentioned below - this analysis uses these to look at the total spread of data.

The issues and effects that can't be taken into account in the data, and hence which form 'noise', and may affect the battery degradation analysis include, but are not limited to:

\section{Measurement accuracy}

- SOC (slight variations in the recorded SOC compared to the actual capacity remaining in the battery)

- Ambient Temperature (records only taken every minute. May also be other variables which affect the temperature gauge)

- The effect of humidity on battery degradation

- Speed (recorded only every minute so difficult to determine how much of an affect this has over a long journey).

Auxiliary loads (Hotel loads)

- This includes the power taken from the battery for the air conditioning and heating as well as additional weight in the car. It is assumed that the same driver will have the same auxiliary load when driving the same journey at the same ambient temperature but this cannot be guaranteed. There is a strong correlation between SOC used on a journey and ambient temperature.

Driving behavior:

- This is the effect of different drivers with potentially different driving styles from the same family. It is assumed that this averages out for the same vehicle, but the data isn't in-depth enough to determine varying behavior.

- Road topology/speed required (i.e. uphill, dual carriageway, motorway, urban)

To try and minimize extraneous effects a number of measures will be taken:

- For this analysis all data $<0^{\circ} \mathrm{C}$ and $>20^{\circ} \mathrm{C}$ is excluded to try and remove the extreme variances of hotel loads. Fig. 8 shows SOC used against ambient temperature for vehicle 1 journeying from home to work. As the temperature increases above $20^{\circ} \mathrm{C}$ the effect of air conditioning load can be seen as an increase in the SOC used.

- Journeys $<5$ miles are excluded from the analysis because it takes a while for the data logger to accurately record the SOC. 
- The SOC usage is not linear and depends on the initial charge conditions. Where possible we use data from vehicles with a high starting SOC.

\section{2) SOC degradation estimate method 1}

Using the data set for vehicle 1, the following data was filtered;

- Same journey (based on distance and GPS start and end points) - Two journeys considered (to work and the return home from work)

- Ambient Temperature set $>0 \mathrm{oC}$ and $<20 \mathrm{oC}$ (to minimise hotel loading effects)

- SOC before journey start $>60 \%$ from home to work and $>$ $80 \%$ for work to home (most of the journeys were undertaken with a SOC of $>92 \%$ because of the opportunity to charge the vehicle at work before commuting)

Using the filtering methods described, only suitable records were analysed. One such journey match, for example, occurred in both Aug 2010 and Aug 2011 with a starting SOC of around $86 \%$ and an ambient temperature of $15^{\circ} \mathrm{C}$, The SOC depletion for the journey in 2010 was $15.3 \%$, whilst the SOC depletion in 2011 was $15.8 \%$. In general terms this means an equivalent journey in 2011 drained the battery more than in 2010 , with $\sim 3 \%$ more energy needed. However, plotting the results of the journey to work as a scatter graph against ambient temperature in Fig. 9 shows no noticeable increase in SOC between the data over each year.

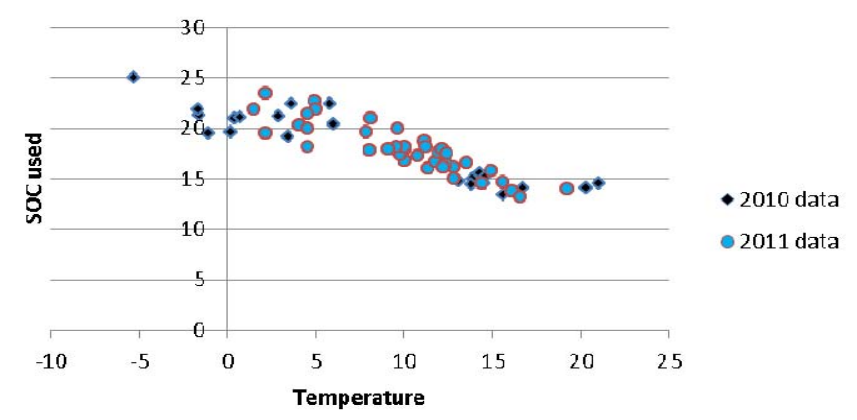

Fig. 7. Vehicle 1 Journey to work

\section{3) SOC degradation estimate method 2}

To allow more data points to be compared, a Monte-Carlo type statistical clustering approach was chosen. Using the data set for seven different vehicles with the same battery size and battery chemistry, the following data was filtered;

- All journeys $>5$ miles

- Ambient Temperature set $>0 \mathrm{oC}$ and $<20 \mathrm{oC}$ (to minimise effects of auxiliary/hotel loading)

- SOC at journey start $>60 \%$

The charge used per mile was calculated for each journey in the three year sets and plotted as shown in Fig. 8. Using the data extracted over 2000 journeys plotted. However, there were less data points in 2010 and 2012 and ideally $>1000$ data points are need for a more accurate analysis.

The results indicate that there is no measurable battery degradation in the vehicles analysed by this method. Had there been some degradation this would have manifested itself as a need for higher energy usage/ $\mathrm{km}$ year on year.

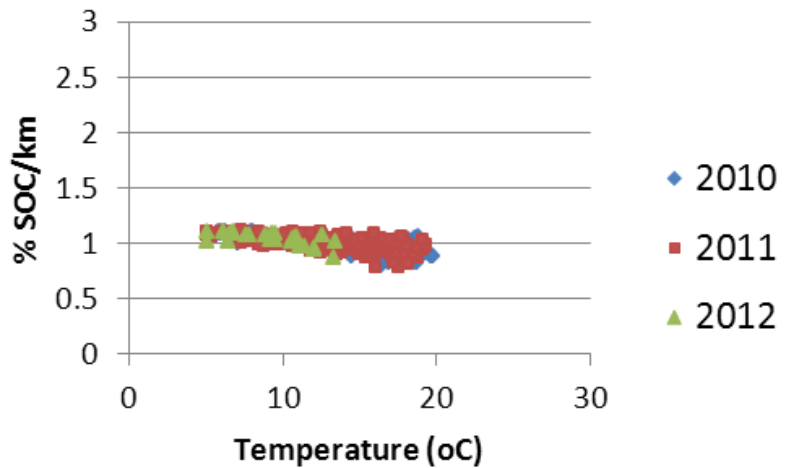

Fig. 8. Vehicle 1: 250 journeys to work showing SOC usage from 2010 to 2012 plotted against temperature.

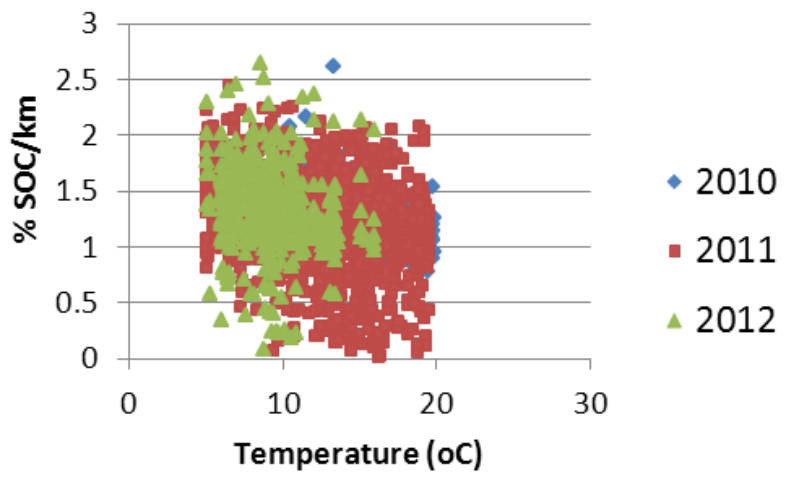

Fig. 9 Vehicle Journey's $>5 \mathrm{~km}$ within ambient temperature boundaries

A brief comparison between Fig 8 and Fig 9 show there is much more of a spread in \%SOC per $\mathrm{km}$ and this reflects the results of different journeys and drivers compared to the specific journey and driver of Fig 8 (for the same battery and vehicle type).

The recorded results for $\% \mathrm{SOC} / \mathrm{km}$ in the cable project are on the high side compared with those by Liaw and Dubarry [13] which are calculated at approximately $0.2 \mathrm{kWh} / \mathrm{km}$ or $0.6 \% \mathrm{SOC} / \mathrm{km}$ in Hawaii. This is not unreasonable as their data is non-temperature specific and based around 15 vehicles within 4 organizations ( 1 of which has strict speed limits) with the same battery type, as opposed to the greater number and variety of CABLED data vehicles. The authors use fuzzy logic within their paper to determine drive cycle and duty cycle profiles to produce a vehicle usage profile which could be used to calculate energy throughput. The advantage of the CABLED data is that the fuzzy logic approach is not needed due to the captured data set. However, a great variety of data points reflecting different driver behavior has been captured.

\section{E. Battery degradation at end of first life - test data}

The tests consider 2 Honda 'Insight' hybrid electric vehicle battery packs which were removed from the vehicles and sent for recycling. The Honda 'Insight' battery is a $6.5 \mathrm{Ah} \mathrm{NiMH}$ battery pack, which utilises 120 Panasonic ' $D$ ' type cells within the pack, configured as 20 series connected strings of 6 cells, fig. 10 . 


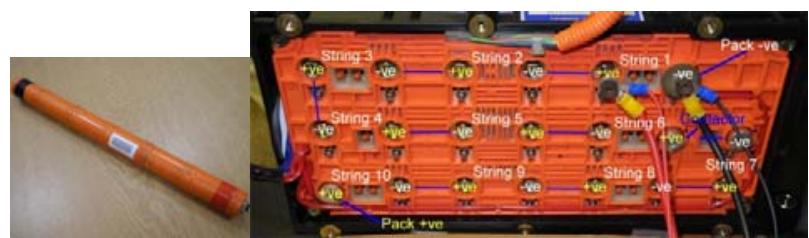

Fig. 10 - String of $6 \times 1.2 \mathrm{~V}$ 'D' Cells from a Honda 'Insight' battery pack.

To reduce the number of tests, and for ease of access of the cells within the packs, the tests were conducted on modules consisting of 2 such 6 cell strings in series, the connections to which were available at one end of the battery pack.

Upon receint the onen circuit voltaoes (nCVs) were measurı Pack 1-Measured OCV's as received ; shown in fig. 11. The OCV's vary between strings and indicate an in balance in the strings within the packs. Subsequent to this, each module was fully discharged to give a known starting point, then fully charged before a controlled discharge was carried out at $\mathrm{C} / 5$ (where $\mathrm{C}$ is the charge rate equal to a battery capacity per hour) to give a measurement of the module capacity. The nominal capacity for the Honda 'Insight' battery pack is $6.5 \mathrm{Ah}$, the voltage curves produced by each module on discharge is included as fig. 12, with the module capacities being graphed as fig. 13 .

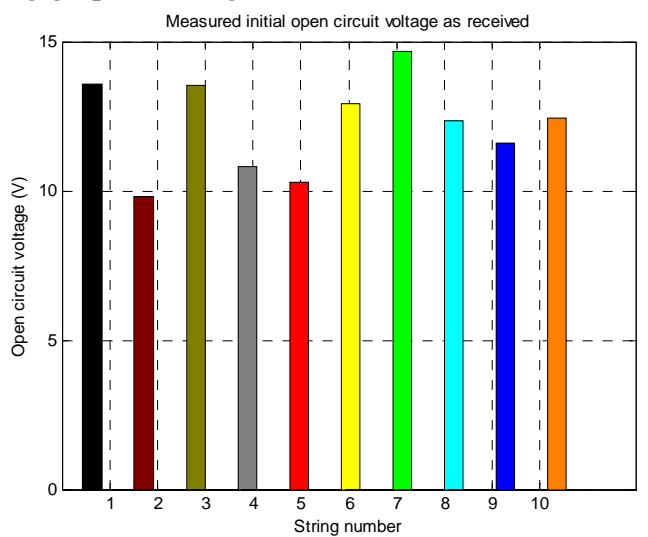

Pack 2 - Measured OCV's as received

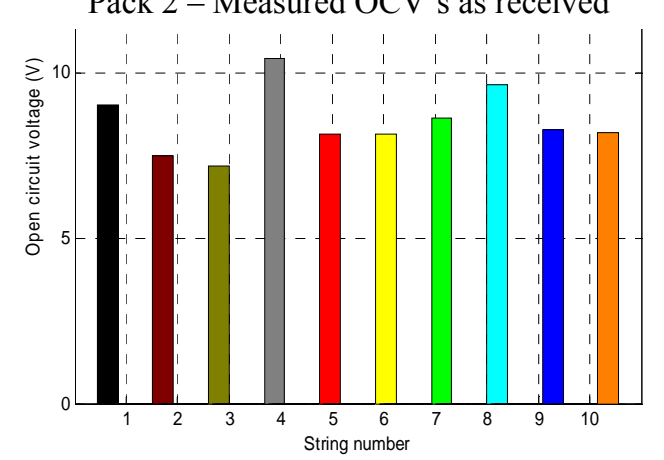

Fig. 11 - OCV's of the 2 Honda Insight Packs as delivered.

The remaining module capacities for the $10 \times 12$ cell battery strings is above $5.2 \mathrm{Ah}$, showing a loss of capacity of a maximum of $20 \%$ on the original pack capacity for the modules. This is in keeping with the generalization that battery packs reach the end of their first life applications when the pack capacities falls to $80 \%$ of the original 'new' pack capacity. Further to the measurements of OCV and module capacity, the modules were then subject to impedance measurements to determine the ability of the modules to provide power on a transient basis. Fig. 14 shows the magnitude of the module impedance against frequency for each of the modules in the battery packs. It can be seen that the module impedances are consistant across the two packs, showing similar trends and values across each of the modules in the packs. Each module having an impedance of approximately $0.1 \Omega$ at $0.1 \mathrm{~Hz}$. This shows the packs are still capable of delivering a significant current despite being nominally at the end of their useful first life.
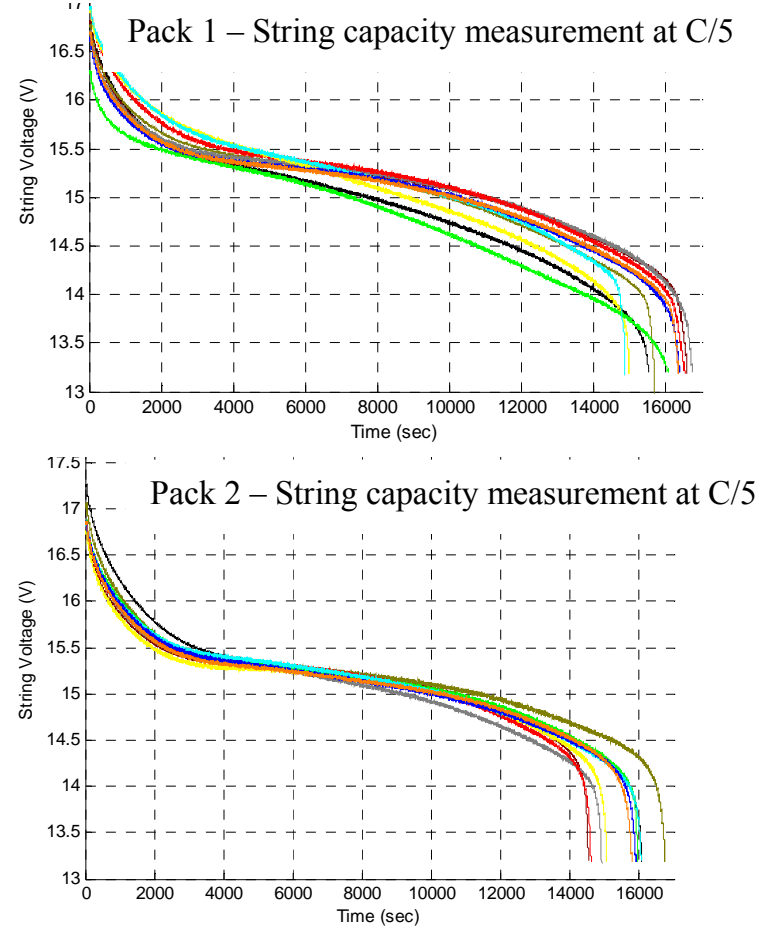

Fig. 12 - Discharge curves for the cell modules in each pack.

\section{BATTERY SECOND LIFE}

Future battery management systems, for example, using techniques under investigation at the University of Maryland, will aim to estimate the remaining life in a much more detailed and comprehensive manner [15]. However, until such times as this is universally adopted within vehicles, estimates are all that is available. Once the battery has completed its 'first life' use - the usage of the second life battery will be different. The number of cycles and the $\% \mathrm{DoD}$ will vary depending on the application and income stream.

\section{A. Ancillary service (or frequency response)}

At present in the UK, National Grid quote that there are around 1500 incidents each year requiring frequency support and this can last up to 30 minutes [14]. However, Fig 15 shows a frequency measurement spread out over the period of a week at one of the distribution substations. Within the week there were 14 incidences of high frequency $(>50.2 \mathrm{~Hz})$ and 7 of low $(<49.8 \mathrm{~Hz})$. This is less than the rate of 1500 incidents/year rate figure quoted by National Grid and each incident lasts less than 5 minutes. The requirement that National Grid has for 30 minutes support is based on rare occurrence. In reality a 10MW unit rated for 30 minutes (the minimum size and time requirement for bidding into the UK market) and operating under a 5 minute window is likely to see a DoD of less than 
Pack 1 -measured string capacity Ahr

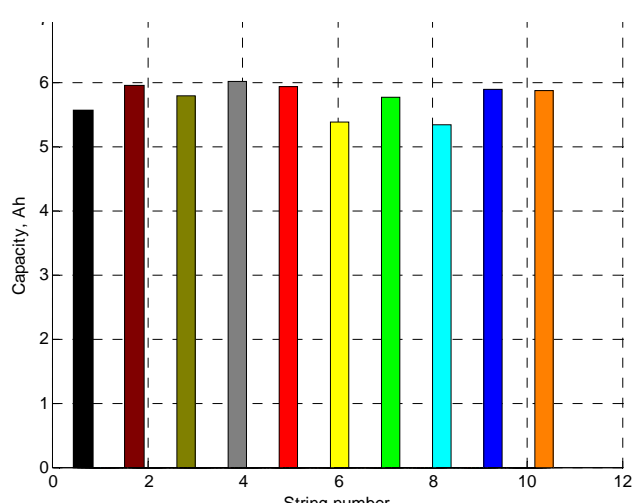

Pack 2 -measured string capacity Ahr

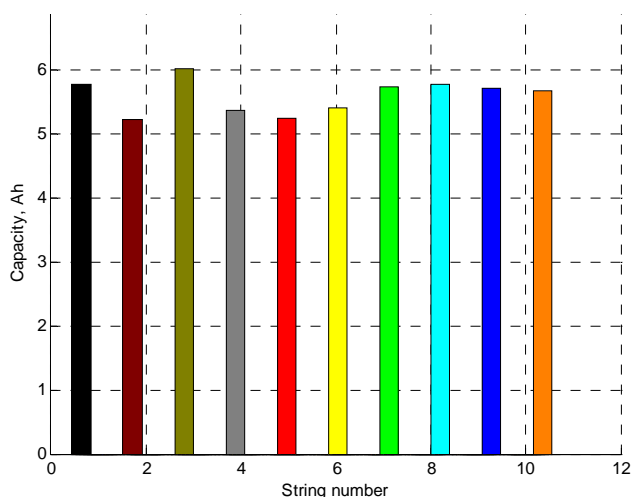

Fig. 13 - Module capacities in the packs.
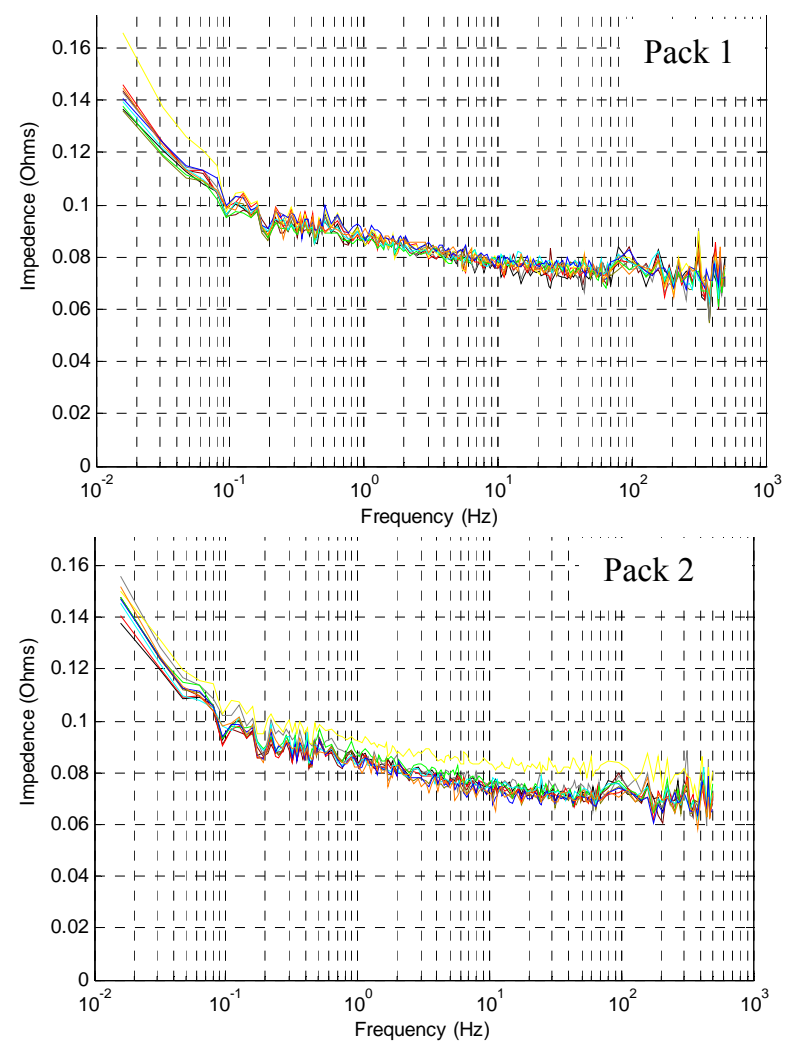

Fig. 14 - Magnitudes of the cell module impedances for the 2 Honda insight battery packs.
$20 \%$ for each low frequency event. Working on the number of events per year at 1500, as quoted By National Grid and assuming that these events are split into 750 over frequency and 750 under frequency events at $20 \%$ DoD the remaining estimated life following first life can be calculated.

From fig. 6 the estimated remaining life after typical vehicle usage is around 900 DoDCE. If it is assumed that the low frequency DoD is $20 \%$ then from equation 2 ,

Remaining: 900 DoDCE

DoD of second life: $20 \%$

Total No Cycles at 20\% DoD : 900/0.2 $=4500$ cycles

No of cycles per year $=1500 / 2=750$

Total years of operation $=4500 / 750=6$ years

This means that the pay back on recycling, battery equipment etc has to be undertaken within a 6 year time scale. The results are shown in Table III.

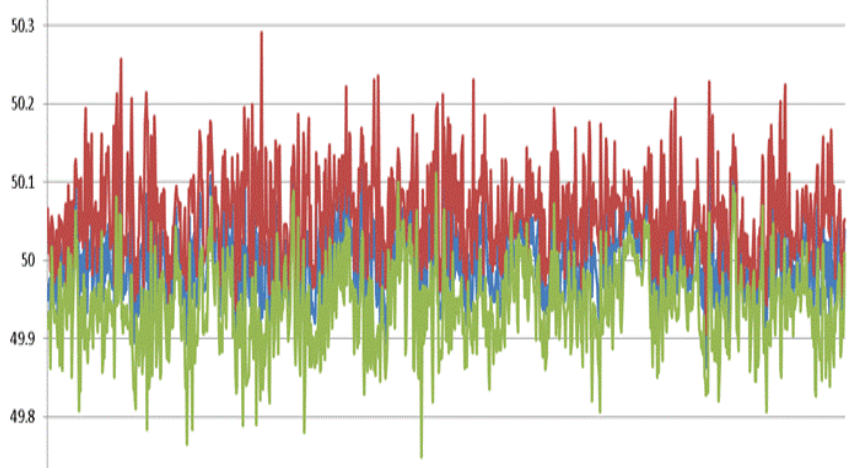

Fig. 15. Typical plot of frequency variation with time over a week, showing maximum, minimum and mean values of frequency over each time segment and the frequency excursions (spikes over $50.2 \mathrm{~Hz}$ and under $49.8 \mathrm{~Hz}$ )

\section{B. Network deferral}

A typical situation is where an energy storage system is designed to charge overnight and discharge at peak time to allow Network deferral costs to be referred to a later date. The battery will be required to charge and discharge once per day to a DoD of say $50 \%$ between the months of November to February to meet peak load on the feeder (typical data from Western Power Distribution [10]). Using the same analysis and assuming that the battery charging/discharging is required for only 4 months of the year allows the following to be calculated:

Remaining: 900 DoDCE

DoD of second life: $50 \%$

Total No Cycles at 50\% DoD: 900/0.5 = 1800 cycles

No of cycles per year $=4 \times 30=120$

Total years of operation $=1800 / 120=15$ years

If it is assumed that frequency response is also an option but is only available outside the months of November to February (incl) then the combination of Network deferral and frequency response results in a life span of 4 years as shown in Table III

\section{Energy management}

Like the network deferral - energy management is likely to occur at peak times but for the whole year. Assuming a factory operating over 5 days per week and a discharge of $50 \%$, this equates to a life cycle of 7 years [10]. Additional charge and discharge criteria can be used [11] but the cases here are 
representative of customers studied. The option of providing frequency support at other times of the year can also be considered. This adds to the energy use pattern of five days per week charging and discharging plus a proportional part of the time spent on frequency support.

TABLE III

Summary of remaining life span

\begin{tabular}{|l|l|l|}
\hline Usage & Second life cycle & $\begin{array}{l}\text { Estimated } \\
\text { remaining life }\end{array}$ \\
\hline A: Ancillary service & 1500 cycles at $10 \%$ p.a. & 6 years \\
\hline B: Network deferral & $\begin{array}{l}50 \% \text { per day for four } \\
\text { months }\end{array}$ & 15 years \\
\hline $\begin{array}{l}\text { Network deferral and } \\
\text { ancillary service }\end{array}$ & Combination of A and B & 4 years \\
\hline C: Energy management & $\begin{array}{l}50 \% \text { per day } 5 \\
\text { days/week }\end{array}$ & 7 years \\
\hline $\begin{array}{l}\text { Energy management and } \\
\text { ancillary service }\end{array}$ & Combination of A and C & 3 years \\
\hline
\end{tabular}

\section{CONCLUSION}

Battery lifespan for a typical driver is thought to be around 10 years. The battery is in use for around 40 minutes per day with an approximate DoD of $35 \%$ with 200 yearly charges. Estimated battery life span until $20 \%$ degradation is 8 years. For a second life application the $\% \mathrm{DoD}$ and number of cycles can be estimated and used to calculate the remaining life span. These figures may be used to calculate the business model for developing the hardware and infrastructure to deal with second life batteries. It should be noted, that battery degradation will be influenced by different chemistries and aging characteristics will vary significantly. This method relies on having a degradation curve available for the battery chemistry. Other limitations of this method include the effect of capacity fade and calendaric aging which has not been taken into account (only cyclic aging has been considered) and the effect of averaging driver usage. Within the CABLED project, out of the sixty vehicles analysed, at least one vehicle will probably not be available for $2^{\text {nd }}$ life applications, while 5 vehicles could have batteries available for a much longer second life than the expected average. Until detailed measurement and analysis of many second life battery systems of different chemistries and manufacturers is connected to the grid and is available these figures will always remain an estimate.

It should also be noted that as the batteries degrade energy efficiency drops to $75 \%$ at $>50 \%$ degradation and this will need to be taken into account.

\section{ACKNOWLEDGMENT}

The authors gratefully acknowledge the contributions of W. Hung (NG), S. Mellor \& J. Taylor (ECA), B. Godfrey (WPD), M. Green (G\&P Batteries) \& P King (TMETC)

\section{REFERENCES}

[1] Arup and Cenex, "Investigation into the Scope for the Transport Sector to Switch to Electric Vehicles and Plugin Hybrid Vehicles", Department of Transport, October 2008.

[2] Shepherd, S., P. Bonsall, et al. (2012). "Factors affecting future demand for electric vehicles: A model based study." Transport Policy 20(0): 6274
[3] Peterson, S.B., Apt, J, Whitacre J.F, "Lithium-ion battery cell degradation resulting from realistic vehicle and vehicle-to-grid utilization", Journal of Power Sources, Elsevier, 2009, pp2385-2392

[4] Weiping Liu; Delacourt, C.; Forgez, C.; Pelissier, S. "Study of graphite/NCA Li-ion cell degradation during accelerated aging tests Data analysis of the SIMSTOCK project", Vehicle Power and Propulsion Conference (VPPC), 2011 IEEE, Page(s): 1 - 6

[5] Haran, B.S.; Ramadass, P.; White, R.E.; Popov, B.N. "Capacity fade of Li-ion cells cycled at different temperatures" Battery Conference on Applications and Advances, 2002. The Seventeenth Annual pp $13-18$

[6] Christophersen, J.P.; Glenn, D.F.; Motloch, C.G.; Wright, R.B.; Ho, C.D.; Battaglia, V.S "Electrochemical impedance spectroscopy testing on the Advanced Technology Development Program lithium-ion cells" Vehicular Technology Conference, 2002. Proceedings. VTC 2002-Fall. 2002 IEEE 56th Page(s): 1851 - 1855 vol.3

[7] RAC National Traffic Survey

[8] Transport, D. f. (2010). "National Travel Survey: 2009."

[9] Jarno D. Dogger, Bart Roossien, Member, IEEE, and Frans D. J. Nieuwenhout "Characterization of Li-Ion Batteries for Intelligent Management of Distributed Grid-Connected Storage" Energy Conversion, IEEE Transactions on Volume: 26 , Issue: 1 Publication Year: 2011 , Page(s): $256-263$

[10] http://lowcarbonvehicles.s3.amazonaws.com/4_John_Taylor.pdf

[11] Keeli, A.; Sharma, R.K. "Optimal use of second life battery for peak load management and improving the life of the battery" Electric Vehicle Conference (IEVC), 2012 IEEE, Page(s): $1-6$

[12] Neubauer, Pesaran,Willimas,Ferry,Eyer "A Techno-Economic Analysis of PEV Second Use:Repurposed-Battery Selling Price and commercial and Indrustial End-User Value", SAE World Congress and exhibition, April 24-26 2012

[13] Liaw, Dubarry "From driving cycle analysis to understanding battery performance in real-life electric hybrid vehicle operation", Journal of Power Sources, Vol 172, Nov 2007, p76-88

[14] http://www.nationalgrid.com/uk/Electricity/Balancing/services/ frequencyresponse/

[15] Xiao-Sheng Si, Wenbin Wang, Chang-Hua Hu, Dong-Hua Zhou and Michael G. Pecht "Remaining Useful Life Estimation Based on a Nonlinear Diffusion Degradation Process", IEEE Transactions on Reliability, Vol. 61, No. 1, March 2012

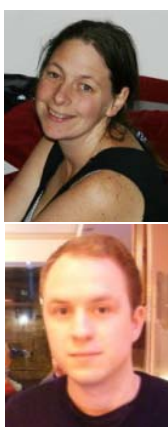

\section{BIOGRAPHIES}

Dani Strickland has worked for Eon, Sheffield University, Rolls Royce Fuel Cells PLC and is currently employed at Aston University as a lecturer.

Laurence Chittock is a final year $\mathrm{PhD}$ student at Aston University. His research involved the development of a location model to site charging points for electric vehicles, and he also undertook the data analysis for the CABLED EV trial. He received his first degree, in Maths and GIS, in 2009 from Aston University.

David A. Stone received the B.Eng. degree in electronic engineering from the University of Sheffield, and a Ph.D. degree from Liverpool University, U.K. He is currently a Professor at University of Sheffield specializing in power electronics and machine drive systems.

Martin P. Foster received a PhD from the University of Sheffield, U.K, in 2003, where he is currently a senior lecturer. His research interests include the modeling and control of power converters and power electronic packaging and thermal management.

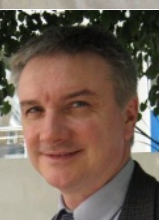

Brian Price is a lecturer at Aston University and an adjunct professor at University of Wisconsin - Madison. Prior to joining Aston University, he worked in industry for 25 years holding a variety of senior engineering leadership positions, included responsibilities for engineering development, roject execution and business leadership, with consultant and manufacturing companies. 